\title{
Corrigendum
}

\section{Structural and functional imaging of the hippocampus in young people at familial risk of depression - CORRIGENDUM}

\author{
Z. N. Mannie, N. Filippini, C. Williams, J. Near, C. E. Mackay and P. J. Cowen \\ doi:10.1017/S0033291714000580. Published online by Cambridge University Press, 7 April 2014.
}

In table 2 of the above article by Mannie et al., the unit of measurement should be cubic $\mathrm{cm}$ instead of cubic mm. The corrected table is published below.

Table 2. Brain volume measures in FH+ participants and controls

\begin{tabular}{lccc}
\hline & FH+ $(n=62)$ & Control $(n=59)$ & $p$ \\
\hline Brain measures, $\mathrm{cm}^{3}$ & & & \\
$\quad$ Total intracranial volume & $1522.1(122.5)$ & $1511.2(105.6)$ & 0.60 \\
Grey matter & $637.7(50.5)$ & $628.9(40.6)$ & 0.29 \\
White matter & $551.7(49.4)$ & $548.6(44.5)$ & 0.72 \\
\hline
\end{tabular}

\section{Reference}

Mannie ZN, Filippini N, Williams C, Near J, Mackay CE and Cowen PJ. Structural and functional imaging of the hippocampus in young people at familial risk of depression. Psychological Medicine, Published online 7 April 2014. doi:10.1017/S0033291714000580. 